\title{
InfLUenCE OF CMM Velocity ON SCANNING PRECision
}

\author{
Melichar Martin, Kubátová Dana, Kutlwašer Jan
}
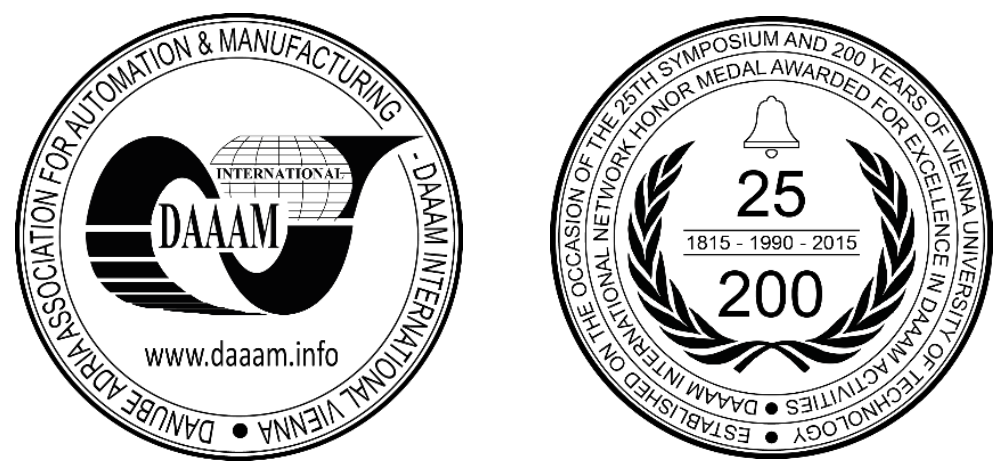

This Publication has to be referred as: Melichar, M[artin]; Kubatova, D[ana] \& Kutlwaser, J[an] (2017). Influence of CMM Velocity on Scanning Precision, Proceedings of the 28th DAAAM International Symposium, pp.0400-0409, B. Katalinic (Ed.), Published by DAAAM International, ISBN 978-3-902734-11-2, ISSN 1726-9679, Vienna, Austria DOI: $10.2507 / 28$ th.daaam.proceedings.056

\begin{abstract}
CMM are one of the basics in today's industrial production based on the control activities of complex products. In particular, the area of parameter evaluation, such as shape and position deviations, point spacing from the 3-D model, as well as simple measurement of dimensions in the drawing documentation can't be imagined without the use of CMM. This article describes experiment of analysing influence of positioning velocity for the collecting of individual parameters. During testing in metrology lab of Regional technological institute in Pilsen had been etalon device tested for different speeds. Analysis was being concerned for basic elements of CMM measuring. Results were evaluated using estimation of measurement device capability.
\end{abstract}

Keywords: CMM; Scanning; Velocity; Precision

\section{Introduction}

In today's industrial production, coordinate measuring machines (CMM) are one of the cornerstones of inspection in most enterprises, being used throughout the manufacturing process. Without a CMM machine, it is difficult to imagine the evaluation of parameters related to simple dimension measurement based on drawings, not to mention more complicated and complex endeavours, such as evaluation of form, location and position deviations or the offset of certain points from a 3D model.

Essentially, 3D measuring machines (CMM) are sophisticated devices which are intended to be operated mainly in the controlled environment of a metrology laboratory. As defined in the ČSN 17025:2005 standard, controlled environment is characterized by a temperature of $20 \pm 2^{\circ} \mathrm{C}$ and a temperature gradient of $1{ }^{\circ} \mathrm{C} /$ hour. Constant temperature of the machine, the environment and the specimen provided in this manner is a key underlying parameter of methodologically correct measurement. Under these controlled conditions, CMMs can ordinarily provide an accuracy down to $0.5+\mathrm{L} / 500 \mu \mathrm{m}$, which is more than sufficient (considering a general-purpose machine) for a majority of technical applications in practice. The impacts of these factors, i.e. the environment temperature, were covered in the article

Another area which deserves attention involves the speeds used in the measuring process. The reason is that the continuously increasing pressure on shorter cycle times has reached the field metrology as well, leading to higher speeds to be used for measurement. It becomes necessary to study the practicability of the ever increasing measuring speeds with respect to not only measuring cycle time but mainly with regard to accuracy, repeatability and bias. 
Expectations of the outcome were based on previous experience of working with earlier types of CMMs which were prone to vibration during travel and to a jolt upon the movement had stopped. Hence, measurement errors and resultant reduced repeatability and bias were expected to occur with increasing speeds.

\section{Methodology or Experimental Procedure}

\subsection{Equipment}

Testing was carried out using the Carl Zeiss Prismo Navigator 7 coordinate measuring machine which is able to be fitted with two variants of detection systems. One of them is a fixed scanning head (Fig. 1) (a scanning system for a single scanning direction; where scanning in other directions than the straight one is required, the probe tip must be rearranged in a star-shaped pattern or T-pattern).

The other system comprises a swivel head (Fig. 2)(a detection capable of rotating the probe tip in the direction of the point of interest). Each of these systems has its specific characteristics which were accepted in this experiment. This paper describes a test conducted exclusively with the indexed scanning system.

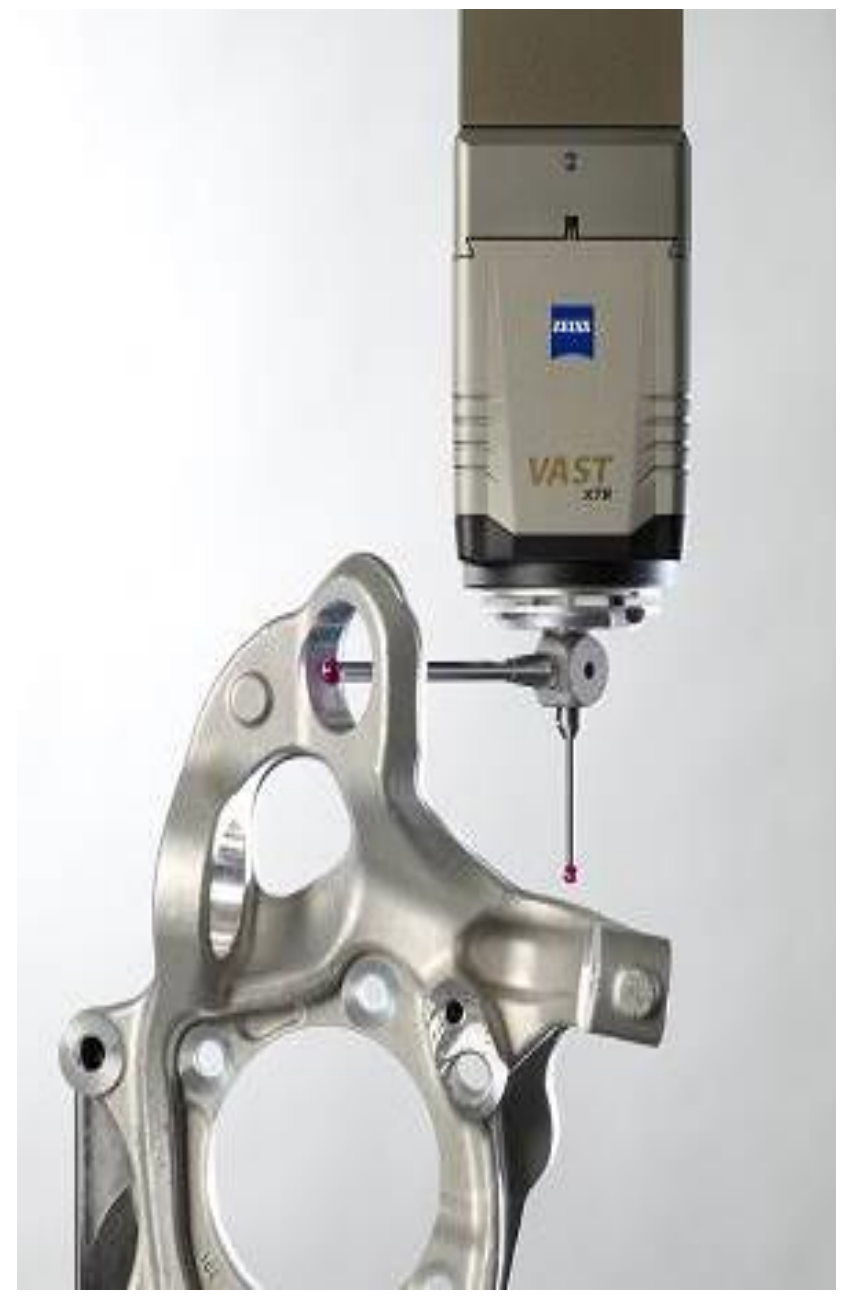

Fig. 1. Fixed head with probe tip[8]

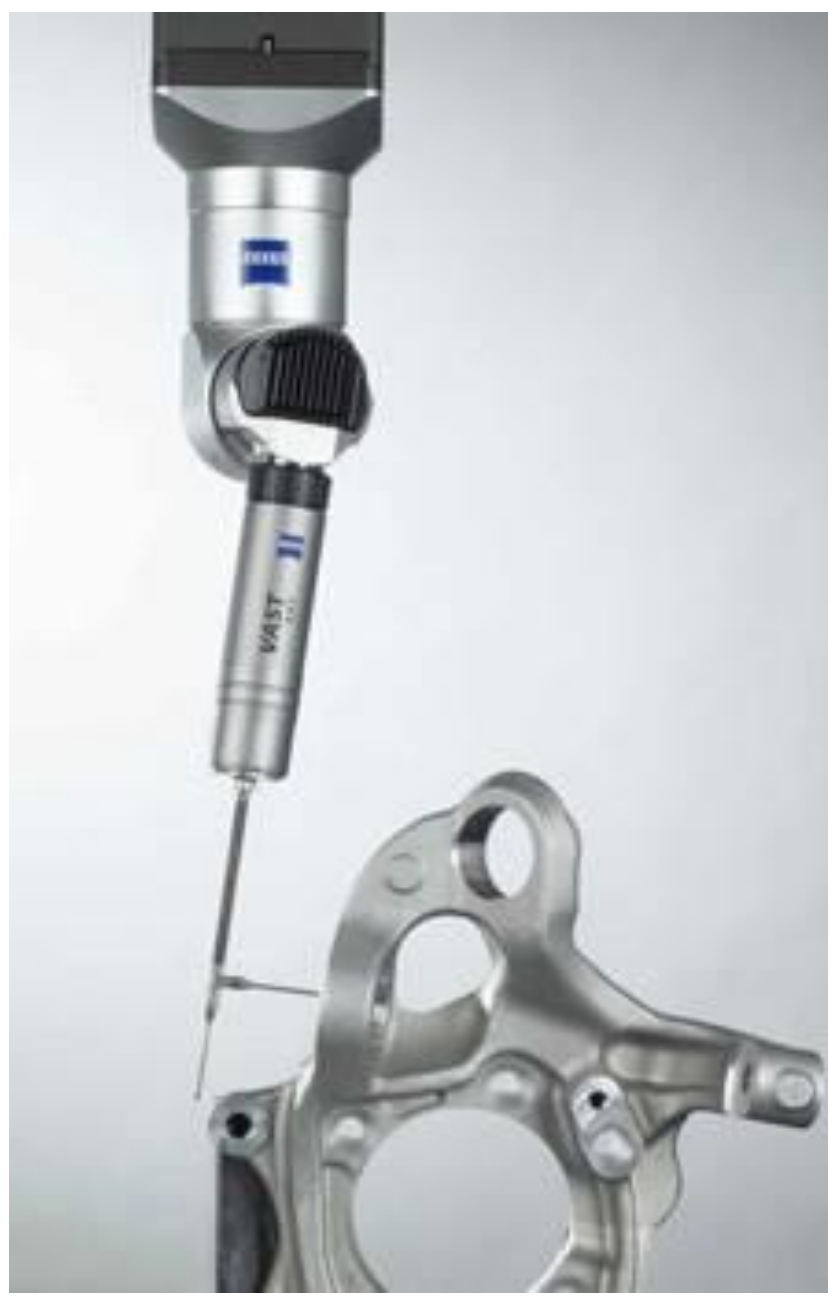

Fig. 2. Swivel head with probe tip[9]

The test item was a cube-shaped reference standard (referred to below as cube) of an aluminium alloy (Fig. 3). The cube was provided with a number of geometric features of known dimensions. These were suitable for making appropriate measurements in order to explore the effect of speed on readings during evaluation of basic dimensions such as length as well as more complex characteristics.[7] Therefore, the effect of speed could also be explored with respect to form, location and position deviations.

The measurements taken on the reference standard included length (large diameter of a cylinder) and form (concentricity of cylinders, flatness of the surface perpendicular to the cylinder axis and straightness). These characteristics were chosen on purpose because they represent typical measurement tasks on, say, engine blocks, gearboxes and pumps. [11] 


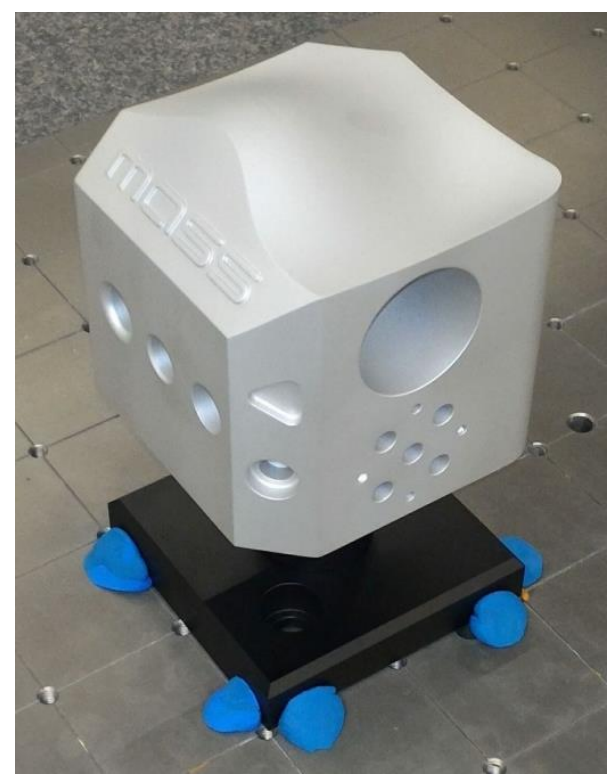

Fig. 3. Tested etalon - Cube

Before the measurement was carried out, the cube had been kept at controlled conditions $\left(20 \pm 2^{\circ} \mathrm{C}\right)$ for 48 hours. It was a sufficient period for thermal stabilisation to eliminate measurement uncertainty due to calculated thermal compensations of the machine. These play, as mentioned in 6;10 article, a major role in machine's accuracy.

\subsection{Measurement parameters}

a) Measuring speeds

$-20 \mathrm{~mm} / \mathrm{min}$

$-40 \mathrm{~mm} / \mathrm{min}$

$-70 \mathrm{~mm} / \mathrm{min}$

The CMM used also offers higher speeds in an "automatic" mode but these have not been ordinarily used for component inspection at the testing facility which is why they have not been employed for this experiment.

b) Point scanning systems

A whole range of characteristics and features can be evaluated using the machine. This experiment, however, only involved the most frequently measured characteristics. Table 1 summarizes selected characteristics of the measurement, including the scanning system and the numbers of points used.

\begin{tabular}{|c|c|c|}
\hline Characteristic & Number of points & Scanning system \\
\hline Mean & 15 & Scan \\
\hline Flatness & 45 & Points \\
\hline Concentricity & $15 / 15$ & Scan / scan \\
\hline Straightness & 5 & Points \\
\hline
\end{tabular}

Table 1. Summary of selected characteristics

\subsection{Verification procedure}

The practicability of the chosen speeds was tested on the above-described "cube" reference standard. For each of the speeds of 20,40 and $70 \mathrm{~mm} / \mathrm{min}, 11$ values were measured which were evaluated subsequently. The first evaluation step only involved the time of measurement. After that, mean values for individual features were calculated, as well as their variance in relation to measurement speed. The next step involved the use of statistical methods where the measuring instrument capability was determined in the form of cg and cgk.

The original plan only concerned the time of measurement, the mean value and variance. That however proved insufficient. Consequently, the calculation of process repeatability (the Cg coefficient) was added. Yet, this parameter alone is insufficient as well. The issue here is that CMM technology exhibits a peculiar phenomenon: the variability between measurement runs does not increase with speed but may even diminish. This can be explained in terms of the 
control system, i.e. the static and, particularly, dynamic corrections applied to the data. Therefore, the information on precision alone $(\mathrm{Cg})$ is not a reliable input for assessing the measuring process. [2,4]

The reason is that the measuring speed is reflected in the resultant value for the component, i.e. in its accuracy. Consequently, the Cgk coefficient must be used for process capability assessment, as it reflects this mechanism.

The indices $\mathrm{Cg}$, Cgk were verified for both heads, using artificially defined tolerances Table 2 . The limit capability value was chosen as follows: cg, cgk $>1.67$. The value for these parameters was intentionally set lower than the typical value of 1.33. It was motivated by the fact that the CMM is used for high-precision measurement and should therefore meet more stringent requirements. [5]

\begin{tabular}{|c|c|}
\hline Characteristic & Ref. value \\
\hline Mean & 40.2 \\
\hline Flatness & 0.01 \\
\hline Concentricity & 0.013 \\
\hline Straightness & 0.01 \\
\hline
\end{tabular}

Table 2. Reference values of characteristics

Evaluation was based on reference values for the reference standard as well as on tolerance ranges and their positions, as indicated in Table 3.

\begin{tabular}{|c|c|c|c|}
\hline Tolerance width & $\mathbf{0 . 1}$ & $\mathbf{0 . 0 5}$ & $\mathbf{0 . 0 1}$ \\
\hline Mean & $40.20 / 40.30$ & $40.20 / 40.25$ & $40.20 / 40.21$ \\
\hline Flatness & $0.01 / 0.11$ & $0.01 / 0.06$ & $0.01 / 0.02$ \\
\hline Concentricity & $0.013 / 0.113$ & $0.013 / 0.063$ & $0.013 / 0.023$ \\
\hline Straightness & $0.01 / 0.11$ & $0.01 / 0.06$ & $0.01 / 0.02$ \\
\hline
\end{tabular}

Table 3. Tolerance range of characteristics and their distribution (lower tolerance limit / upper tolerance limit)

Three procedures are available for calculating the capability of the measuring instrument cg and cgk. These are the procedures according to Škoda Auto a.s., FORD and GM. This experiment was based on the procedures used at the FORD company, Fig. 4 shows the relationships between capability indices and the tolerance range. The upper part of the figure shows the tolerance range $\mathrm{T}$ of the measurand and its limits LSL and USL. (T = USL - LSL). In evaluating the measuring instrument, only a part of this range is considered, represented in Fig. 4 as 20\%, i.e. 0.2T, the same as in evaluating the test. The bottom of the figure shows an enlarged representation of this segment of the range. It contains the mean value from readings taken repeatedly on the reference standard $\bar{x} g$ and the reference value of the standard $\mathrm{xr}$, which is sometimes referred to as xm (see Fig. 4). The 6Sg interval should be sufficiently smaller than the segment of the specification field under consideration. The value of $6 \mathrm{Sg}$ represents an interval, in which - assuming Gaussian distribution of the error of measurement - contains $99.73 \%$ of values. [1,3,4]

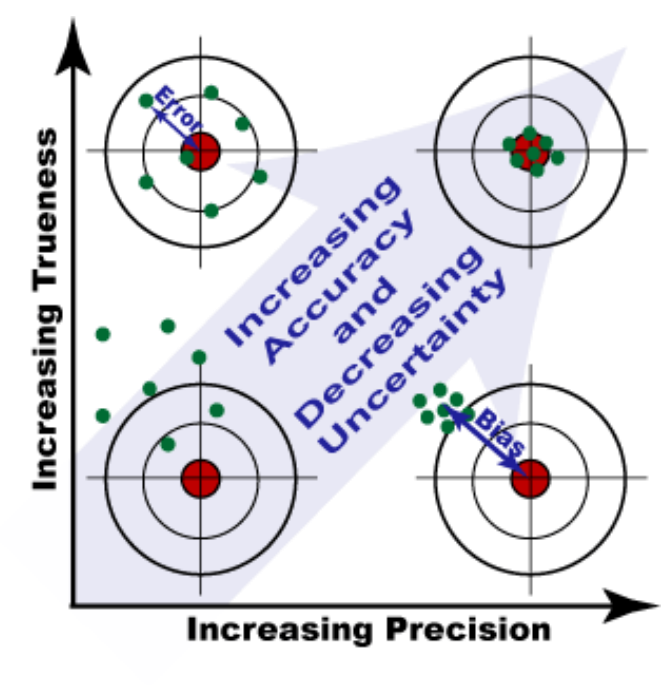

Fig. 4. Graphical representation of the statistical method of calculating the measuring instrument capability 
Ford method formulae for calculation with the tolerance range T:
a) Sample standard deviation $S_{g}=\sqrt{\frac{1}{n-1} \sum\left(x_{i}-\bar{x}\right)^{2}}$
b) Variance
$\mathrm{S}=\mathrm{s}_{\mathrm{g}}^{2}$
c) Arithmetic mean value
$\overline{\mathrm{x}}=\frac{1}{\mathrm{n}} \sum \mathrm{x}_{\mathrm{i}}$
d) Repeatability
$c_{g}=\frac{K * T}{6 s_{g}}$
e) Bias

$$
c_{g k}=\min \left\{\frac{\left(x_{r}+0,075 T\right)-\bar{x}}{3 s_{g}} \mid \frac{\bar{x}-\left(x_{r} 0,075 T\right)}{3 s_{g}}\right\}
$$

$\mathrm{n}$... number of measured values

xi...value of xth reading

$\mathrm{x}$ bar ... arithmetic mean value

xr...reference value of the standard

$\mathrm{T}$...tolerance range width

$\mathrm{K}$...constant in the range of $10-30 \%$ defines the width of the tolerance range for calculation

\section{Evaluation of the experiment}

The evaluation sequence comprised the following steps. In each evaluation step, the actual values were converted into point scores on a scale from one to three. The higher the number of points, the poorer the result.

The first evaluation step for this test involved determining the time required for measurement at various speeds. The measuring times in Table 4 are times required for a single measuring cycle (program). Point scores were assigned in line with the above-described arrangement.

\begin{tabular}{|c|c|c|}
\hline Speed & Measuring time & Result \\
\hline 20 & $42 \mathrm{~min}$ & 3 \\
\hline 40 & $17 \mathrm{~min}$ & 2 \\
\hline 70 & $13 \mathrm{~min}$ & 1 \\
\hline
\end{tabular}

Table 4. Measuring times and their point scores

This initial evaluation step was followed by ranking on the basis of mean values and variance for individual characteristics under measurement. Table 5 indicates the actual mean values and variances for individual characteristics and measuring speeds.

\begin{tabular}{|c|c|c|c|c|c|c|}
\hline & \multicolumn{2}{|c|}{$\mathbf{2 0}$} & \multicolumn{2}{c|}{$\mathbf{4 0}$} & \multicolumn{2}{c|}{$\mathbf{7 0}$} \\
\hline & mean value & variance & mean value & variance & mean value & variance \\
\hline Mean & 40.19373977 & $9.56918 \mathrm{E}-09$ & 40.19323585 & $1.14424 \mathrm{E}-08$ & 40.1935387 & $2.59506 \mathrm{E}-09$ \\
\hline Flatness & 0.010920845 & $3.87182 \mathrm{E}-09$ & 0.010969845 & $1.0583 \mathrm{E}-09$ & 0.010920473 & $6.62968 \mathrm{E}-09$ \\
\hline Concentricity & 0.008227182 & $3.26466 \mathrm{E}-07$ & 0.008505027 & $1.92269 \mathrm{E}-07$ & 0.008505027 & $1.92269 \mathrm{E}-07$ \\
\hline Straightness & 0.009515355 & $2.09533 \mathrm{E}-09$ & 0.009514591 & $2.04718 \mathrm{E}-09$ & 0.009514591 & $2.04718 \mathrm{E}-09$ \\
\hline
\end{tabular}

Table 5. Actual mean values and variances for the speeds of 20,40 and $70 \mathrm{~mm} / \mathrm{min}$

The mean values and variance values were converted into point scores in such manner that higher values (poorer result) led to higher point scores. Table 6 this is the outcome of the conversion. 


\begin{tabular}{|c|c|c|c|c|c|c|}
\hline & \multicolumn{2}{|c|}{$\mathbf{2 0}$} & \multicolumn{2}{c|}{$\mathbf{4 0}$} & \multicolumn{2}{c|}{$\mathbf{7 0}$} \\
\hline & mean value & variance & mean value & variance & mean value & Variance \\
\hline Mean & 3 & 3 & 1 & 1 & 2 & 2 \\
\hline Flatness & 2 & 2 & 3 & 1 & 1 & 3 \\
\hline Concentricity & 3 & 3 & 1 & 1 & 1 & 1 \\
\hline Straightness & 3 & 3 & 1 & 1 & 1 & 1 \\
\hline
\end{tabular}

Table 6. Point scores for mean values and variance values

The last table summarizes the results for the combination of the mean value and variance. Based on this calculation, Table 7 shows that if we only considered these two characteristics, our initial expectation would clearly be confirmed. i.e. the higher the speed, the higher the variance and the poorer the mean value. Not even this data. However, is in full agreement with our expectation: with straightness, higher speed leads to a better result. Nevertheless, it is important to consider the measuring experiment as a whole and identify the optimal speed for the entire measurement. This is why it was appropriate to also consider measurement precision (expressed by the cg parameter) and accuracy (expressed by cgk) and not only the readings.

\begin{tabular}{|c|c|c|c|}
\hline & $\mathbf{2 0}$ & $\mathbf{4 0}$ & $\mathbf{7 0}$ \\
\hline Mean & 3 & 1 & 2 \\
\hline Flatness & 2 & 2 & 2 \\
\hline Concentricity & 3 & 1 & 1 \\
\hline Straightness & 3 & 1 & 1 \\
\hline Result & $\mathbf{2 , 7 5}$ & $\mathbf{1 , 2 5}$ & $\mathbf{1 , 5}$ \\
\hline
\end{tabular}

Table 7. Summarized evaluation of mean value and variance

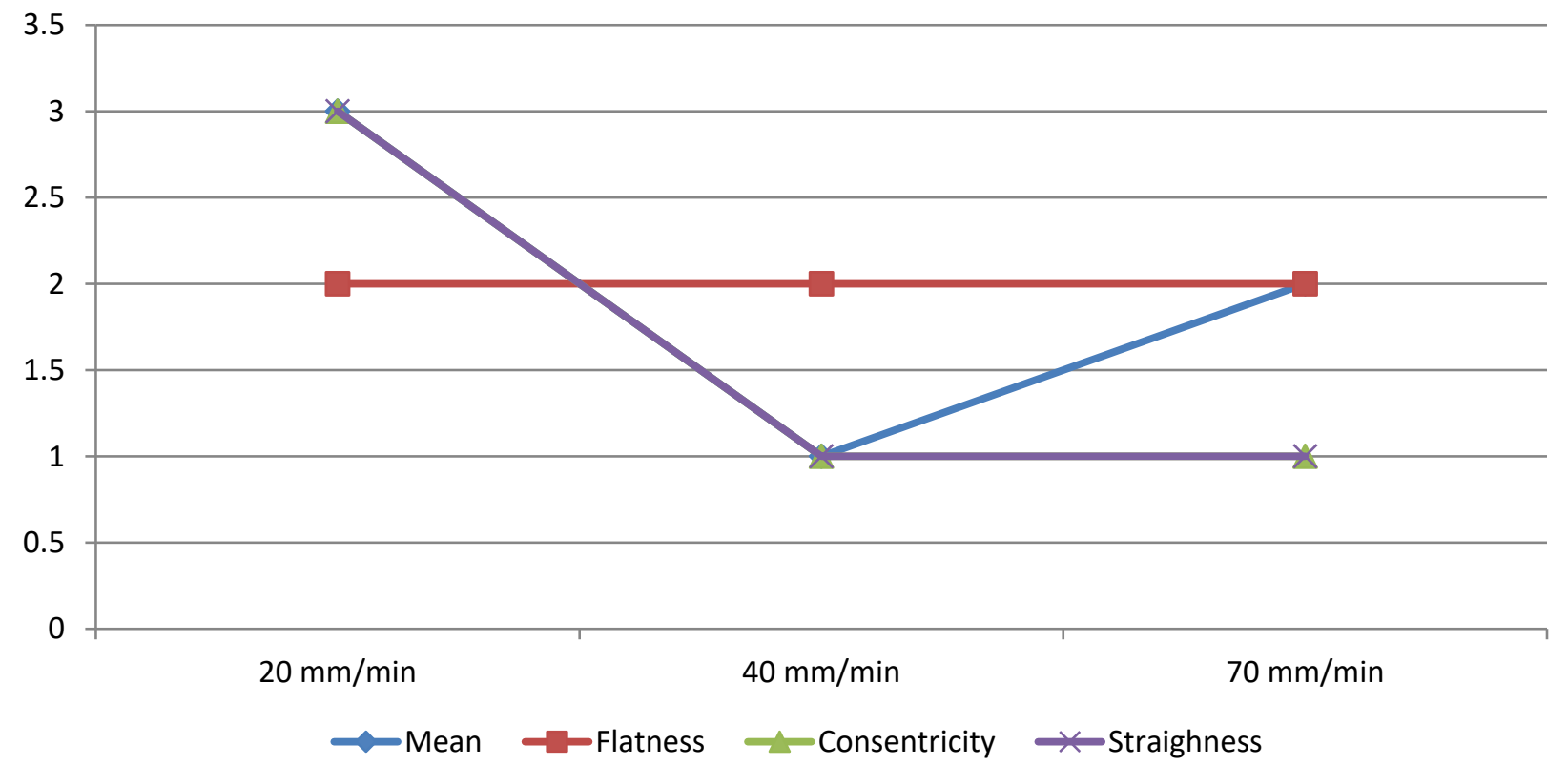

Graph 1. graphical representation of mean value and variance

The measuring instrument capability calculation took into account three widths of the measuring instrument tolerance ranges. Here, only the results for the lowest tolerance range value. $0.01 \mathrm{~mm}$. are reported. With this width, the results began to be satisfactory. Furthermore, the values are essentially the same for the other 2 tolerance ranges but two and four times larger.

The evaluation used the same procedure as that of the mean value and variance. Table 8 again lists the actual calculated repeatability and reproducibility values according to the procedure outlined above. 


\begin{tabular}{|c|c|c|c|c|c|c|}
\hline & \multicolumn{2}{|c|}{$\mathbf{2 0}$} & \multicolumn{2}{c|}{$\mathbf{4 0}$} & \multicolumn{2}{c|}{$\mathbf{7 0}$} \\
\hline & Repeatability & Bias & Repeatability & Bias & Repeatability & Bias \\
\hline Mean & 17,03771312 & 4,224578413 & 15,58081388 & 2,293014214 & 32,71711856 & 6,796654 \\
\hline Flatness & 26,78496808 & 35,24448889 & 51,2324748 & 66,91119563 & 20,46927221 & 26,93563 \\
\hline Concentricity & 2,916953882 & 4,242895045 & 3,800968745 & 5,317534541 & 3,800968745 & 5,317535 \\
\hline Straightness & 36,41014189 & 51,08601088 & 36,83584585 & 51,67767789 & 36,83584585 & 51,67768 \\
\hline
\end{tabular}

Table 8. Actual repeatability and bias values for the speeds of 20.40 and $70 \mathrm{~mm} / \mathrm{min}$

They were also assigned point scores but it should be pointed out that in this case the procedure was different. Here. higher value did not receive more points. It was the opposite: the higher the repeatability or reproducibility. the better. and the lower the number of points.

\begin{tabular}{|c|c|c|c|c|c|c|}
\hline & \multicolumn{2}{|c|}{$\mathbf{2 0}$} & \multicolumn{2}{c|}{$\mathbf{4 0}$} & \multicolumn{2}{c|}{$\mathbf{7 0}$} \\
\hline & Repeatability & Bias & Repeatability & Bias & Repeatability & Bias \\
\hline Mean & 2 & 2 & 3 & 3 & 1 & 1 \\
\hline Flatness & 2 & 2 & 1 & 1 & 3 & 3 \\
\hline Concentricity & 3 & 3 & 1 & 1 & 1 & 1 \\
\hline Straightness & 3 & 3 & 1 & 1 & 1 & 1 \\
\hline
\end{tabular}

Table 9. Point conversions for repeatability and bias of measurement

The last table shows the aggregate results for the combination of repeatability and bias of measurement. This calculation reported in Table 10 shows that if we only took into account these two parameters, our expectations would have been disproved. The aggregate result indicates that the best speed was $40 \mathrm{~mm} / \mathrm{min}$.

\begin{tabular}{|c|c|c|c|}
\hline & $\mathbf{2 0}$ & $\mathbf{4 0}$ & $\mathbf{7 0}$ \\
\hline Mean & 2 & 3 & 1 \\
\hline Flatness & 2 & 1 & 3 \\
\hline Concentricity & 3 & 1 & 1 \\
\hline Straightness & 3 & 1 & 1 \\
\hline Result & $\mathbf{2 , 5}$ & $\mathbf{1 , 5}$ & $\mathbf{1 , 5}$ \\
\hline
\end{tabular}

Table 10. Summary of evaluation of repeatability and bias

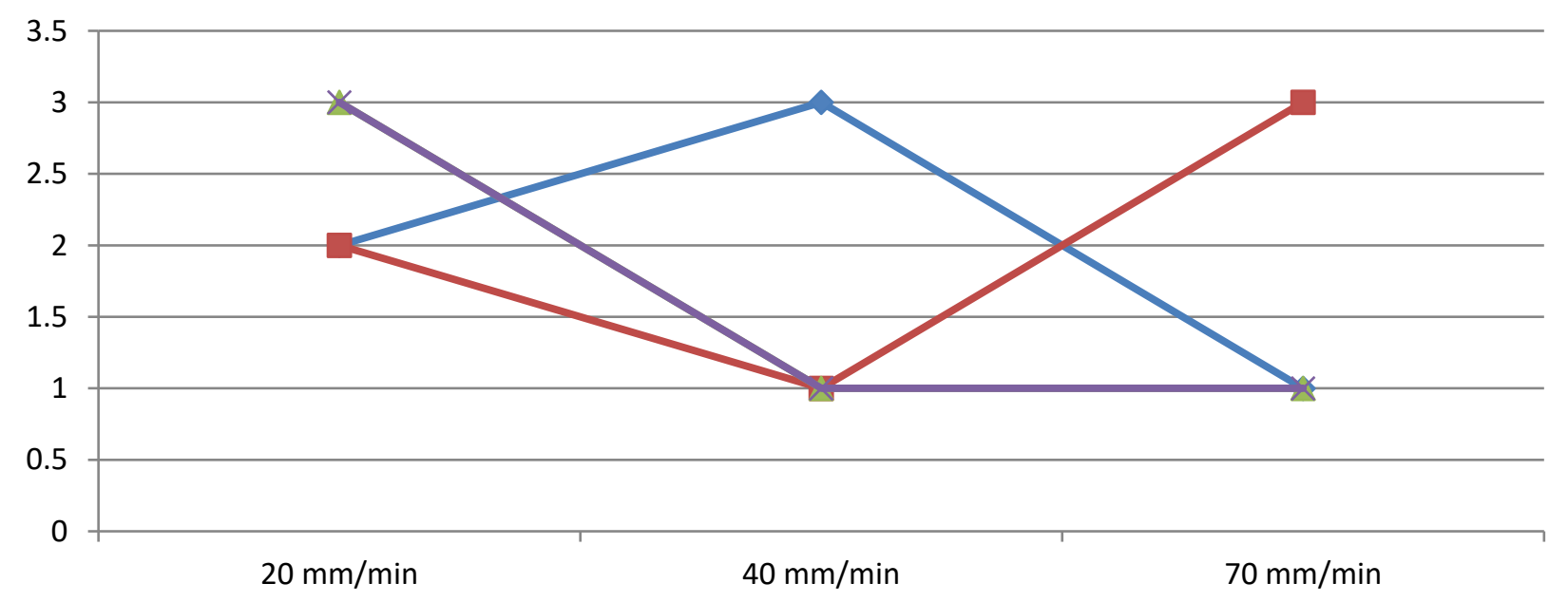

$\sim$ Mean $\multimap$ Flatness $\multimap$ Consentricity $\longleftarrow$ Straighness

Graph 2. Graphical representation of results for repeatability and bias 
The last two tables indicate overall results of the fixed head test. Table 11 shows point scores of the case where only accuracy, repeatability and bias of measurement were reviewed.

In this case, our hypothesis has been proved. Using lower speed provides better measurement values.

On the other hand, the difference between $20 \mathrm{~mm} / \mathrm{min}$ and $40 \mathrm{~mm} / \mathrm{min}$ is not that striking. What is more, if this result is complemented with the point scores for the measuring time, as shown in Table 11,

Table 12 the picture becomes completely different.

\begin{tabular}{|c|c|c|c|}
\hline & $\mathbf{2 0}$ & $\mathbf{4 0}$ & $\mathbf{7 0}$ \\
\hline Result based on mean value and variance & 2,75 & 1,25 & 1,5 \\
\hline Result based on repeatability and bias & 2,5 & 1,5 & 1,5 \\
\hline Result & $\mathbf{2 , 6 2 5}$ & $\mathbf{1 , 3 7 5}$ & $\mathbf{1 , 5}$ \\
\hline
\end{tabular}

Table 11. Summary of the comparison of results I.

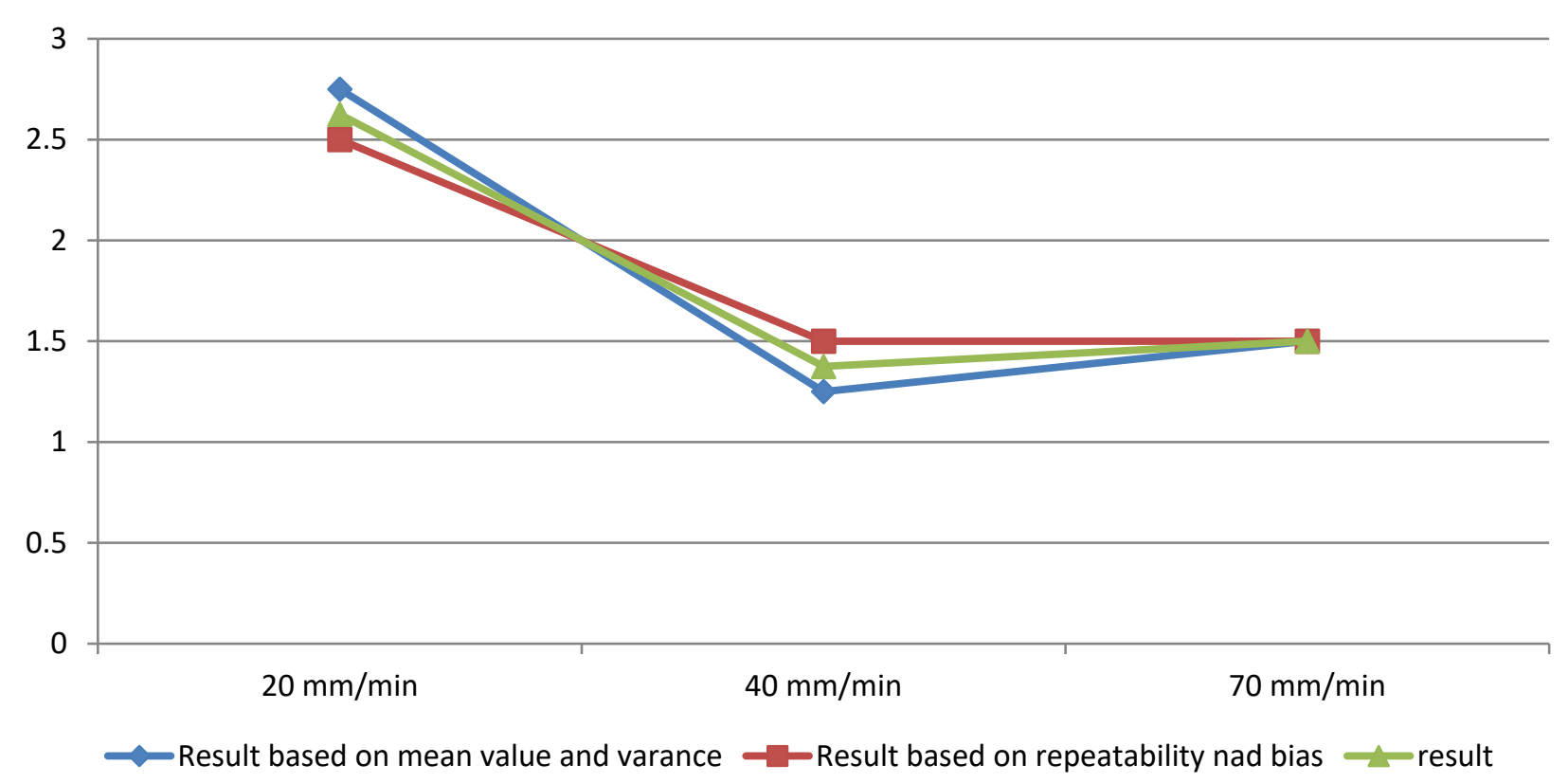

Graph 3. Summary of the comparison of results I

If this result is complemented with the point scores for the measuring time, as shown in Table 12, the picture becomes completely different.

The best one is now the measurement at the speed of $70 \mathrm{~mm} / \mathrm{min}$.

\begin{tabular}{|c|c|c|c|}
\hline & $\mathbf{2 0}$ & $\mathbf{4 0}$ & $\mathbf{7 0}$ \\
\hline Result based on measuring speed & 3 & 2 & 1 \\
\hline Result based on mean value and variance & 2,75 & 1,25 & 1,5 \\
\hline Result based on repeatability and bias & 2,5 & 1,5 & 1,5 \\
\hline Result & $\mathbf{2 , 7 5}$ & $\mathbf{1 , 5 8 3 3 3 3 3 3 3}$ & $\mathbf{1 , 3 3 3 3 3 3 3 3 3}$ \\
\hline
\end{tabular}

Table 12 . Summary of the comparison of results II. 


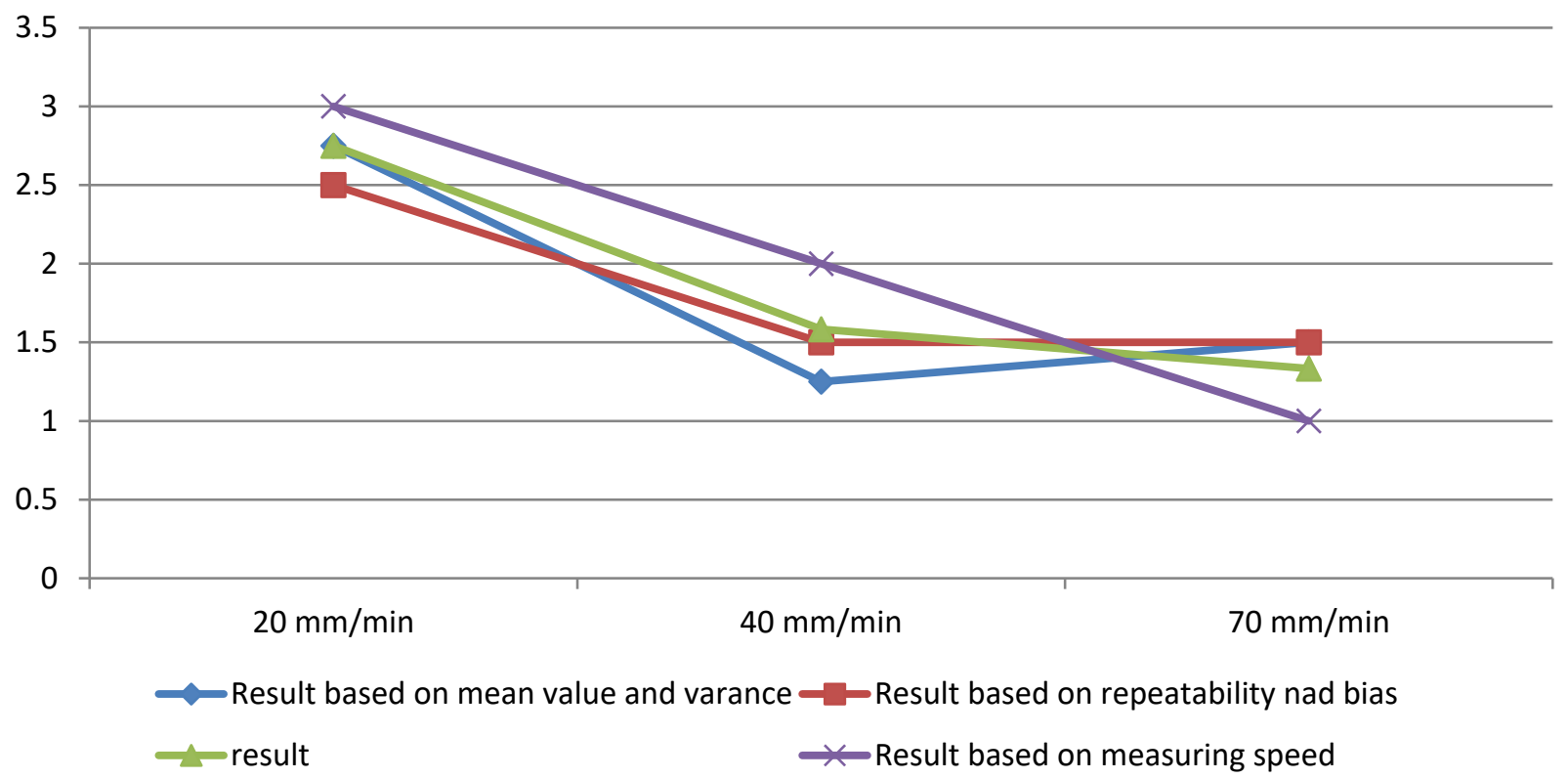

Graph 4. Summary of the comparison of results II.

\section{Conclusions}

Considering the comprehensive and time-consuming CMM-based inspections in production where machine parts are ordinarily checked with respect to hundreds of characteristics and the measuring times alone often reach tens of minutes of several hours on intricate components, opportunities for improvement are certain to exist in measuring centres, which can be brought to fruition by optimizing scanning speeds. Yet, such an effort must be undertaken with respect to the particular machine, for a particular configuration of the scanning system, specific characteristics of the part with prescribed tolerances and. where possible, by an experienced operator. It is therefore important to understand the capabilities and deficiencies of CMM settings.

This paper deals with an evaluation of the effects of measuring speed on reading accuracy was carried out as part of a research programme at the University of West Bohemia/Faculty of Mechanical Engineering/Regional Technological Institute. The actual evaluation of the test was based on point scores assigned to the data obtained, whether they represented the measuring times, mean values, variance, repeatability or bias and their combinations as well.

The test was based on an assumption that the measurement precision decreases with increasing measuring speeds (in our case. the speeds of 20.40 and $70 \mathrm{~mm} / \mathrm{min}$ were chosen).

Our assumption was confirmed in part. This was in the case when the test evaluation only considered the mean value and variance. i.e. when actual dimensions were taken into account. Here, when all measured characteristics were evaluated as a whole, the speed of $20 \mathrm{~mm} / \mathrm{min}$ (i.e. the minimal measuring speed) was confirmed. Yet, a closer look at individual characteristics offers a less clear-cut picture: for instance, the evaluation of straightness shows that better results are obtained at a higher speed $(70 \mathrm{~mm} / \mathrm{min})$.

This is why the test evaluation also used the processing based on measuring instrument capability (cg. cgk parameters). The minimum limit for these parameters was set at 1.67. All parameters calculated for all tolerance ranges met this value. However, when just repeatability and bias are considered, the result is not that definitive. Here, the point scores identified the speed of $40 \mathrm{~mm} / \mathrm{min}$ as the best one.

Since the choice of measuring speed must be viewed in its entirety and one cannot choose different speeds for different characteristics, it is necessary to take a decision in each case and strike a compromise between the measuring speed, precision or repeatability.

Our test with the Carl Zeiss Prismo 7 Navigator machine fitted with a fixed head yields a recommendation that an appropriate compromise between these parameters and a chosen speed is the speed of $40 \mathrm{~mm} / \mathrm{min}$.

This experiment descripted in this paper is next step in larger study of measurement influencing factors.

\section{Acknowledgements}

The article contribution has been prepared under project LO1502 'Development of the Regional Technological Institute'under the auspices of the National Sustainability Programme I of the Ministry of Education of the Czech Republic aimed to support research, experimental development and innovation. 


\section{References}

[1] Melichar M.. Kubátová D.. Kutlwaše J.: (2016). CMM measuring cycle and human factor. Proceedings of the 27th DAAAM International Symposium. ISBN 978-3-902734-08-

[2] Perníkář J.: Assessment of the competence of control means [online]. [cit. 2016-11-25]. Available from: http://gps.fme.vutbr.cz/STAH_IN FO/31_Pernikar_VUTBR.pdf

[3] Płowucha W.. Jakubiec W.. Wojtyła M.: Possibilities of CMM Software to Support Proper Geometrical Product Verification. Procedia CIRP. Volume 43. 2016. Pages 303-308. ISSN 2212-8271. http://dx.doi.org/10.1016/j.procir.2016.02.124

[4] Barini M. E.. Tosello G. Chiffre d L.: Uncertainty analysis of point-by-point sampling complex surfaces using touch probe CMMs: DOE for complex surfaces verification with CMM. Precision Engineering. Volume 34. Issue 1. January 2010. Pages 16-21. ISSN 0141-6359. http://dx.doi.org/10.1016/j.precisioneng.2009.06.009 .

[5] Jiroušek P.: Eligibility of measurement system in the gearboxes production of Škoda auto a.s [online]. 2012 [cit. 2017-03-08]. Available from:https://is.savs.cz/lide/clovek.pl?zalozka=13;id=148; studium=2015. Diplomová práce. ŠKODA AUTO a.s. vysoká škola.

[6] Kubátová D.. Melichar M.. Kutlwašer J: Evaluation of Repeatability and Reproducibility of CMM Equipment.

[7] Yu. C.-T \& Ma. C.-M \& Cheng. B.-W. (2009). An evaluation method of contact measurement system of the coordinate measuring machine (CMM). Journal of Quality. 16. 213-221.

[8] https://www.interempresas.net/Automotive/Companies-Products/Product-Measuring-probes-Zeiss-VAST-XTR96591.html [online 18.9.2017]

[9] https://www.zeiss.cz/metrologie/produkty/senzory/vast-xxt.html [online 18.9.2017]

[10] Melichar M., Kubátová D., Kutlwašer J.: Influence of temperature compensation for evaluation using influence of temperature compensation for evaluation by continuous scanning.

[11] http://www.engineering.sk/clanky2/stroje-a-technologie/3188-vliv-rychlosti-snimani-na-zpusobilost-procesukontroly-geometrickych-specifikaci-s-vyuzitim-cmm [online 18.9.2017]

[12] https://www.nde-ed.org/GeneralResources/ErrorAnalysis/UncertaintyTerms.htm [online 22.9.2017] 